\title{
Difficulties in patch antenna production and prototyping in Turkey
}

\author{
Gökberk Kemal Oğuz ${ }^{1^{*}}$ \\ ${ }^{1}$ Industrial Policies and Technology Management, Istanbul Commerce University, Turkey
}

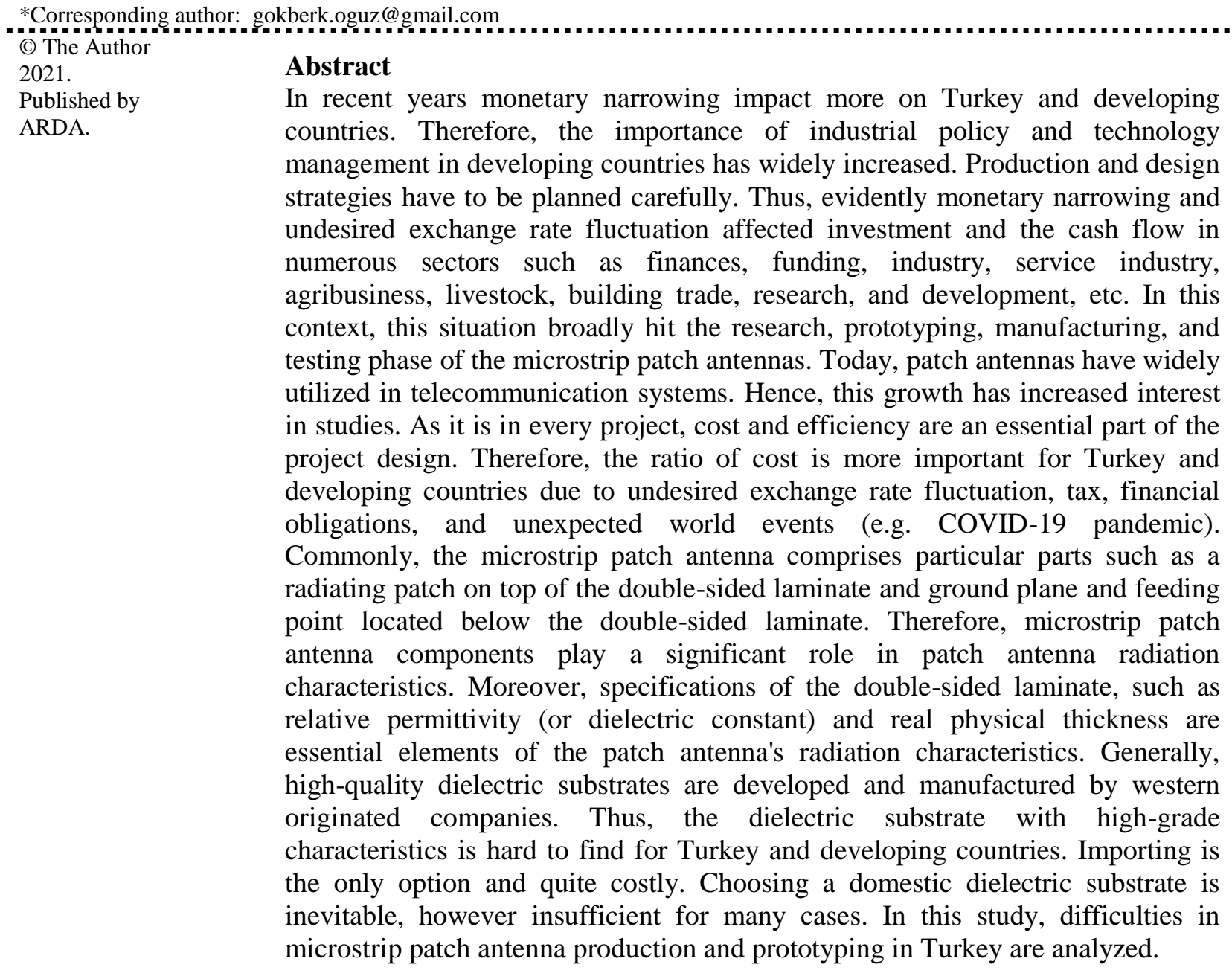

Keywords: Microstrip patch antenna, Telecommunication systems, Production and prototyping, Difficulties, Turkey

\section{Introduction}

Within recent decades, microstrip patch antennas have been quite popular, and they have widely taken part in telecommunication. Furthermore, patch antennas are lighter, smaller, and more durable than other antennas (dish, yagi, loop, whip, et cetera) apart from all, patch antennas implementable in almost every condition and shape. Hence, microstrip patch antennas are highly typical in almost every sector including military applications. They are utilized in almost every field, from aviation, mobile devices, wearable devices, and implants to radar systems, etc. Accordingly, in the near future, patch antennas will take over conventional antennas in every area. In this context, this growth has increased the interest in microstrip patch antenna

This work is licensed under a Creative Commons Attribution License (https://creativecommons.org/licenses/by/4.0/ ) that allows others to share and adapt the material for any purpose (even commercially), in any medium with an acknowledgement of the work's authorship and initial publication in this journal. 
studies in research groups and laboratories. Commonly, the patch antenna has particular parts; for instance, in the first layer radiating patch placed on top of the double-sided laminate, in the second layer, there is a dielectric substrate placed between first and third layers and lastly on the third layer ground plane located with feeding point. Therefore, the patch antenna's components characteristics can interfere with performance parameters. Moreover, the double-sided laminate's (dielectric substrate) specifications indicate that dielectric constant and actual physical thickness are essential elements of the microstrip patch antenna's radiation characteristics. The substrate with high-grade characteristics is hard to find for Turkey and developing countries. Since importing option is quite costly. Choosing a domestic dielectric substrate is inevitable, however insufficient for some applications. As it is in every project, cost and efficiency are a vital part of the project design. Therefore, the ratio of cost is more important for Turkey and developing countries due to floating exchange rates. Consequently, monetary narrowing, undesired exchange rate fluctuation and recent coronavirus (COVID-19) pandemic broadly hit the research, prototyping, manufacturing, testing, and the supply chain of the microstrip patch antenna industry.

\section{Difficulties in patch antenna production \& prototyping}

In today's period, microstrip patch antennas are one of the commonly used antenna types. All around the world, study and research groups study on microstrip patch antennas. Since, in terms of structure, it is preferably light, durable and can even be positioned in curved surfaces than other types of antennas. From early 2000, RF engineers found new ways to resolve major drawbacks and of microstrip patch antennas. Thus, soon microstrip patch antennas going to catch conventional antennas then rise above [1]. Patch antennas are quite popular devices. Besides, microstrip patch antennas have utilized in numerous fields, including national defense moreover, patch antennas are used in many different fields such as satellite communication, medical, telecommunication, cosmology, public transportation, aviation, aircraft defense systems, and electronic warfare et cetera. In recent years, the fluctuation in currency rates and monetary narrowing has caused major problems in antenna design and production in developing countries. This situation affected more the smallscale industries and mostly individuals such as students and low-budget researchers. Traditionally, the antenna design starts with substrate selection and built on the substrate. The rareness of high-quality dielectric substrates in the domestic market is one of the main reasons for this situation. There are various difficulties in the design and production of patch antenna. Designing a microstrip patch antenna with compact size, high gain, and providing a wideband frequency range is a difficult case. The essential shortcomings of patch antenna are inefficient radiation, low gain, limited bandwidth. To overcome significant drawbacks, the RF engineer selects dielectric substrates with low dielectric constant. Thus dielectric substrates with low dielectric constant increase the radiation efficiency, antenna gain, and directivity. Nevertheless, the high-grade dielectric substrates with a low dielectric constant are rare and expensive than high dielectric constant substrates. A high dielectric constant substrate is inexpensive and common. Moreover, High dielectric constant dielectric substrates reduce gain and directivity; however, it increases bandwidth [2]. To overcome the narrow bandwidth issue, the RF engineer applies optimization techniques. Multi-layer feeding methods such as proximity coupling, aperture coupling increase the bandwidth of the microstrip patch antenna. By applying multi-layer feeding methods, the designer adds a high dielectric constant substrate to the microstrip patch antenna's structure. Consequently, high dielectric constant feeding formation increases the patch antenna's bandwidth [3].

\subsection{Literature review and foundation of the work}

This research describes the difficulties faced by Turkey during the production and prototyping process of microstrip patch antennas. The study's foundation is based on the experience gained during the author's previous [4] and [5] works. Correspondingly, literature scans continued. Economic studies such as [6], [7], [8], [9], and [10] were examined. The impact of fluctuations in foreign exchange and taxes on imports in 
Turkey was examined. Accordingly, the result of these effects on the production and prototyping process of patch antenna in Turkey has been revealed.

\subsection{Growing interest in microstrip patch antenna}

Telecommunication systems are an important part of our daily life. In everyday life, mobile phones are widely used and are part of the telecommunication system. Mobile phones are widely hailed for their technological benefit to mankind, the ease it creates in doing daily chores, and most of all, bridging of information as well as communication gaps among people [11]. In this context, the most important part of the telecommunication systems are patch antennas. Patch antennas are highly preferred; the most significant reason for these is that microstrip patch antenna can be designed according to any condition. In addition, patch antennas are durable and manufactured easier and more affordable than other antennas. As they are widely used in many fields, studies and developments on these antennas have increased. They are designed and manufactured in universities, research groups, RF laboratories, small-scale industry and production facilities affiliated to largescale companies. Accordingly, there are companies that produce and develop RF substrates that are essential in the patch antenna prototyping. By conducting researches, companies develop RF materials for antennas to be used for different purposes. Some of the USA based companies that have developed high-quality materials are Rogers Corp, Taconic and Arlon EMD.

\subsubsection{Survey on microstrip patch antenna publications}

Now, microstrip patch antennas are highly common antennas in the RF domain. Microstrip patch antennas are used in many areas. For instance, in civil applications, cellular communication, surveillance systems, medicine, public transportation, id tags, and many more. In military applications, radar systems, missile systems, aircraft, land vehicles, et cetera. By virtue of patch antenna's benefits, for instance, appliable to almost every surface and condition, lightweight, durable, producible via conventional PCB techniques, microstrip patch antennas have become a popular antenna type in RF engineering. George Deschamps discovered the idea of patch antenna in the 50s. Afterward, microstrip patch antenna patented by Gutton $\&$ Baissinot; however, until the 70s, proper patch antenna prototype did not come out because of the lack of specifications of dielectric substrates. Furthermore, the early prototype developed by Munson and Howell in the 70s. In the 80s, the world entered the golden era of personal computers since this situation escalated the development of microstrip patch antenna [12]. It is essential to mention main events in the timeline briefly:

- In 1981, the RF engineers discussed the method of moments, finite element method, and numerical analysis for advanced analysis of microstrip patch antennas. Moreover, the RF engineers studied microstrip patch antenna analysis models, for instance, cavity and transmission line models [13].

- In 1986, RF engineers worked on increasing the limited bandwidth for some applications and applied the aperture coupling feeding technique to the microstrip antennas; thus, they managed to increase the bandwidth over $\% 50$ [14].

- In 1991, RF engineers found new mathematical expressions to implement performance parameters of microstrip patch antenna, such as radiation pattern, impedance matching [15].

Notable developments have been achieved as a result of these researches. As a result of the obtained developments, new modeling and simulation methods have been found. Computer processors, which are getting faster and faster, have also contributed to this situation. With the integration of new methods found in end-user software, computer programs in the patch antenna modeling process have increased. After these innovations, the development process is no longer dependent on private companies' laboratories. Now, patch antennas can be designed efficiently by undergraduate study groups and workshops within the university. In addition to the design process, there have been improvements in the test phases. With these innovations' help, 
the patch antenna modeling process is considerably shortened and spread over a broad base. Thus, interest in patch antenna studies has increased.

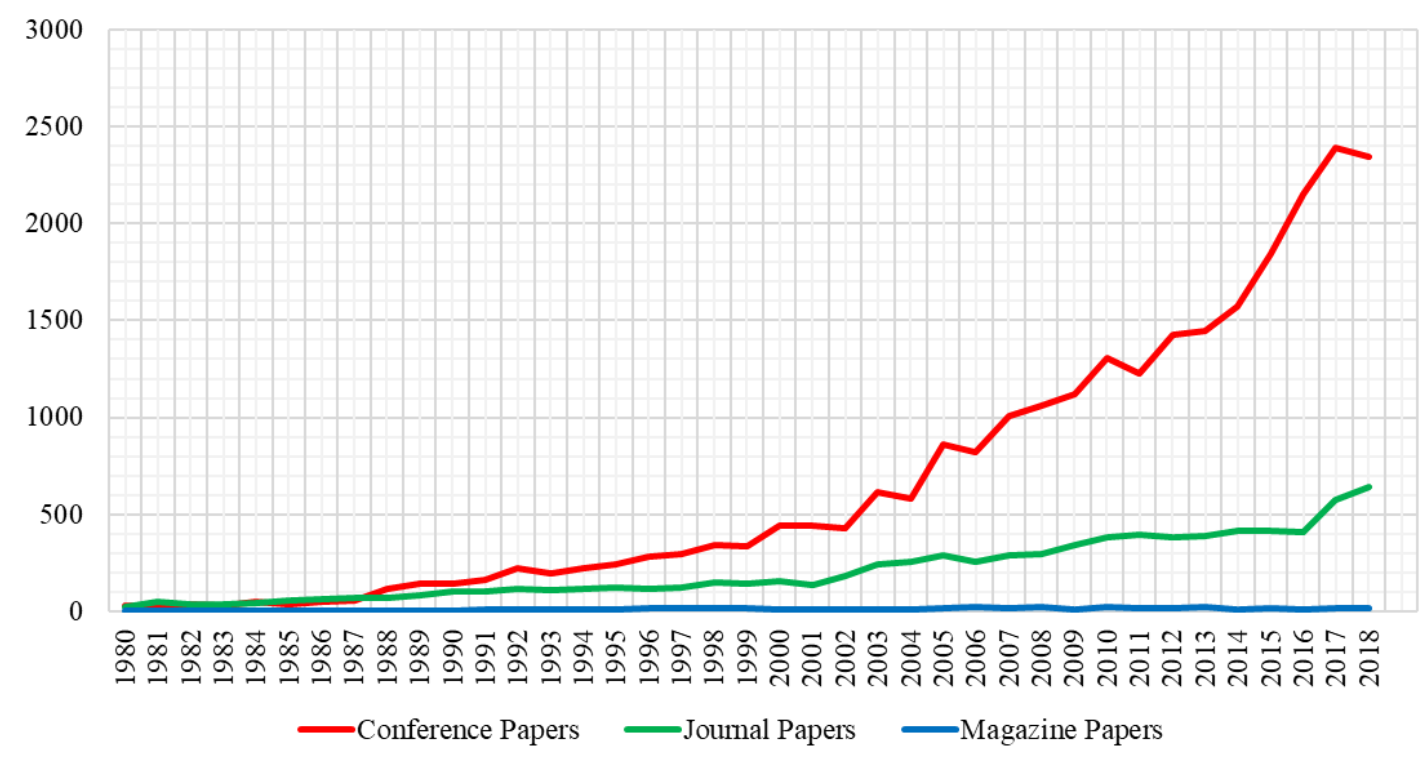

Figure 1. Number of patch antenna papers indexed in IEEE Xplore ${ }^{\circledR}$ Digital Library between 1980-2018

As can be seen in Figure 1., according to the data collected from [16, Fig. 1], there has been a great increase in antenna research and studies since the 1980s. In the 80s golden era of personal computers accelerated the dielectric substrate (double-sided laminate) development. New discovered substrate used in microstrip patch antenna to meet with new communication methods frequency requirement. Moreover, this development also reduced the cost of patch antenna [17]. In this sense, this increase is also developing in parallel with the development of high-quality substrates. Furthermore, the rapid progress of telecommunication and satellite communication systems has accelerated the antenna studies. As described in [18], the development of PCB production and the increase of portable devices have led to the need to produce RF circuits cheaper. Increased computerization in the 1980s accelerated the antenna design, and the modeling process became easier. Consequently, the researchers worked on techniques and new approaches to increase the bandwidth of patch antennas, reduce losses and increase efficiency.

\subsection{The effect of currency fluctuation on antenna design and prototyping in Turkey}

Exchange rate is the ratio of two separate currencies. Undesired foreign exchange rate variation effects are crucial in developing countries. Moreover, variations in the exchange rate directly impact the entire process of business and industrial policies in developing companies with import dependency. Undesired foreign exchange rate fluctuation increases the foreign trade deficit since the foreign exchange rate increase, reduces imports in developing countries [19]. In this context, this circumstance effects microstrip patch antenna project budgeting, research, design, and prototyping process. The main element in patch antenna design and prototyping is the double-sided laminate (dielectric substrate). However, unfortunately, high-grade, low dielectric constant substrates are not available in Turkey's domestic market. Import is the only option. Undesired variation in the exchange rates impact the balance between import and export, inevitably increases domestic product prices. Furthermore, high-grade dielectric substrates mostly developed by USA based companies, and this situation impact the microstrip patch antenna prototyping and manufacturing process in Turkey. Undesired fluctuations in the exchange rate also affect the patch antenna printing process. Generally, patch antennas are produced using printed circuit board printing techniques. The operation caps of the printing machines wear out quickly in the antenna printing process. The tip heads need to be refreshed periodically. Since the printing tips are not available in the domestic market, they have to be imported through suppliers. In this context, these negative effects caused by unwanted fluctuations in the exchange rate affect researchers, 
laboratories and students in the universities. Consequently, fluctuations in currency slow down Turkey's adapt to this trend.

\subsubsection{Effects of currency fluctuation on foreign trade}

Foreign trade is one of the most discussed topics in the economy. Many factors affecting foreign trade have pulled the attention of economists. One of these factors is the undesired fluctuation in foreign currency. The economist comprehensively discusses that unwanted fluctuation in foreign currency affects foreign trade. In the literature, the researcher examined the impacts of foreign exchange rate fluctuation in foreign trade. There are methodical and empirical works available. However, there is no strict regulation about it. Furthermore, according to some studies increasing foreign currency rate reduces import inversely; some works support the opposite approach [20]. Along with this approach, this section will examine the effects of the fluctuation in foreign currency on microstrip patch antenna production, which is dependent on imports.

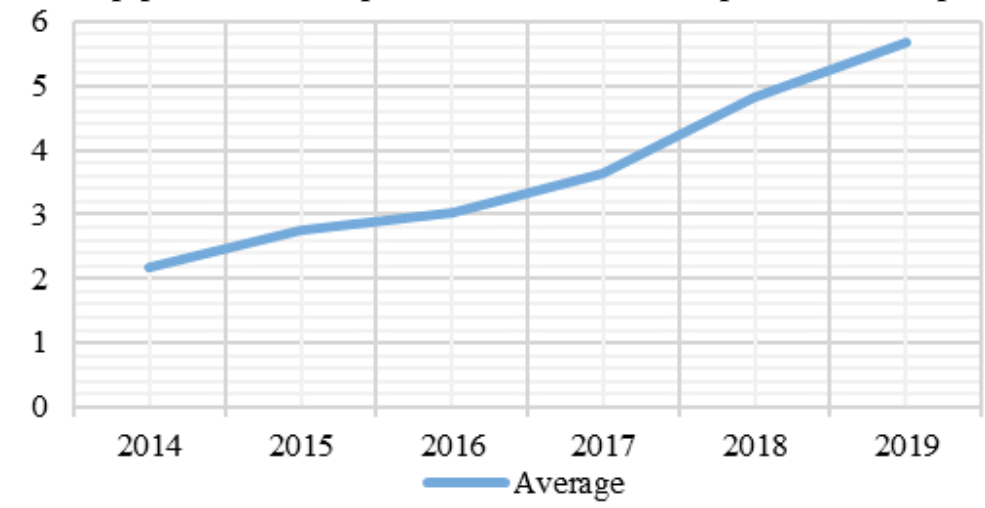

Figure 2. Average USD/TRY exchange rates between 2014-2019

Figure 2., shows a summary of USD/TRY exchange rates between 2014-2019. The data in Figure 2 are based on the exchange rate on the last day of each month [21, Fig. 2]. As will be noticed, the fluctuation has stimulated since May 2018. As seen in the general average, the increase continues and almost stable. When this situation is correlated with the growing interest in patch antennas; the following situation arises, this negative increase is inversely proportional to the growing interest in patch antennas. This is a concrete indicator of a disadvantage for Turkey and other developing countries. In this survey, the real part of the exchange rate is not included because the domestic-variant of high-grade double-sided laminates does not become available in the domestic industry. Countless studies have been conducted in the literature revealing the relationship of interest rates to imports and exports accordingly; this involves foreign trade. However, there are studies in the literature that determine that interest rates affect the exchange rate. Within this context, these circumstances affecting the exchange rate affect the patch antenna industry as in other areas. As previously stated in previous sections, the effects of foreign exchange rates on foreign trade are essential topics in the economy. Occasionally, exchange rates used to analyze foreign trade deficit [22]. Foreign trade and exchange rates are mutually dependent [23]. In the 80s, Turkey switched to an open economic model. Correspondingly, the gap in the foreign trade deficit had first seen, and this situation still stands and one of the main difficulties in Turkey's economy.

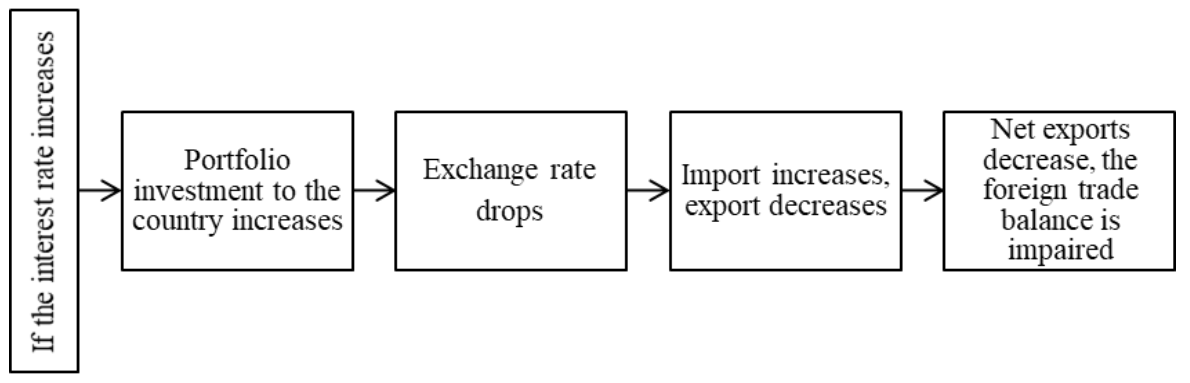

Figure 3. Effects of increase of interest on exchange rate and foreign trade 
As graphically presented in Figure 3. [24, Fig. 3], the interest rates which grew due to the strict financial policies implemented by the countries may induce more portfolio investment flowing to the developing countries besides, causes the growth in the amount of foreign currency and the decrease in the exchange rates. Variation in the pricing of domestic goods against undesired exchange rate fluctuation is an excellent indicator to analyze foreign trade [25]. As a consequence, it is expected that developing countries exports will decrease then, imports will increase, and foreign trade balance will be negatively affected thus, this situation directly affects the patch antenna industry, whose main foundation is a dielectric substrate. The undesired exchange rate fluctuation affects the foreign trade deficit in Turkey. Consequently, observing the state of foreign exchange rates and interest rates are essential parameters in financial analysis. Inflation is another topic that connected to this matter. Moreover, inflation, foreign trade deficit, unemployment, and growth are correlated topics since widely covered in the literature. The pass-through effect describes the connection between foreign exchange rate and inflation. Furthermore, fluctuation in the foreign exchange rate has visible effects on pricing in domestic goods [26]. This long term noticeable effect is proof of inflation's susceptibility to the undesired foreign exchange rate fluctuation. Foreign exchange rate fluctuation affects domestic good's pricing directly and indirectly. Moreover, an increase in the foreign exchange rate reduces imports; this situation raises the production cost and value of domestic goods in local currency [27]. In this context, import dependency of production increases the effect of pass-through effect, i.e., the scale of imported goods as an input in production affects the magnitude of the pass-through effect [28]. Thus, the exchange rate fluctuation has massive consequences of imported goods prices. The indirect effect is highly noticeable in export. If the share of export increases, the price of domestic goods decreases. As domestic goods continue to lose its value, imported goods value will become expensive. In this case, domestic demand will shift to exported and imported substitute goods. The pass-through effect is a dynamic subject that can change from time to time in many different conditions. Pass-through effect is frequently seen in developing countries where the entire industry is based on imported goods [29].

\subsubsection{Dielectric substrate market and industry analysis}

For many years, in industrial countries, designers and manufacturers have been working together to fabricate dielectric substrates at affordable prices. Despite this, as proposed in [30], results that would reduce costs have not been resolved. While this is the case, this matter affects developing countries more. High-quality substrates can only be obtained through imports; therefore, their costs are high. In previous sections, alternation in the foreign exchange rate, inflation, and pass-through effect discussed. There is an additional effect that is tax and financial liabilities in imports. Tax in the imports majorly hits the import of the dielectric substrate because there are many tax elements in imports. Some of those tax elements are; customs duty, value-added tax, special consumption tax, stamp duty, anti-dumping tax, banderole fee, countervailing charges etcetera. Moreover, tax is a dynamic thing that can vary from term to term [8]. Considering this situation, it turns out that the importing high-quality substrate is major financial stress in the patch antenna design and prototyping projects. Substrate suppliers appear to have variable substrate prices. The main reason for this condition is that the substrate stocks are limited. Manufacturers determine the stock according to the demand in the market.

Table 1. Price comparison of high-quality substrates

\begin{tabular}{lcccc}
\hline Name of the substrate & $\begin{array}{c}\text { Dielectric } \\
\text { constant }\end{array}$ & Dimensions & Thickness & Price \\
\hline Rogers Corp RT/duroid 5870 & 2.33 & $202 \times 228 \mathrm{~mm}$ & $0.254 \mathrm{~mm}$ & $\$ 73.09$ \\
Taconic TLX-9 & 2.5 & $305 \times 457 \mathrm{~mm}$ & $0.760 \mathrm{~mm}$ & $\$ 109.25$ \\
Rogers Corp CuClad 217 & 2.17 & $228 \times 305 \mathrm{~mm}$ & $0.380 \mathrm{~mm}$ & $\$ 95.38$ \\
\hline
\end{tabular}


Table 1. shows the current high-grade dielectric substrate prices have taken on [31, Table 1]. As shown in the table, high-grade substrates are quite costly. As briefly mentioned before, it is directly associated with the negative impact of the currency fluctuation on patch antenna design and prototyping. Furthermore, it was observed that the import of dielectric substrates was affected by the price increase caused by the exchange rate fluctuation. This situation displays an increase in project costs in developing countries, including Turkey.

\subsubsection{Suppliers}

When designing the microstrip patch antenna at specific radio frequencies, the essential point is choosing a substrate that determines microstrip patch antennas performance. Besides, it takes an essential part in microstrip antenna performance. The dielectric substrate is the backbone of the patch antenna. As discussed in previous sections, specifications of a dielectric substrate, such as dielectric constant and physical thickness, directly affect the microstrip patch antenna's performance parameters. Commonly, for microstrip patch antennas, the special dielectric sibstrates are used. The price of these dielectric substrates are higher than the basic flame retardant 4 epoxy substrate. The production and supply of special dielectric substrates are carried out by well-established companies. The vast majority of these well-established companies (active more than 60 years) are of USA based companies. Therefore, substrates can be supplied through these companies; besides, there is a quota/limit which suppliers can provide. When financial liabilities in the import and undesired currency fluctuations added to this matter, the patch antenna production and prototyping in Turkey has negatively affected.

Table 2. List of high-grade dielectric suppliers \& corresponding products

\begin{tabular}{|c|c|}
\hline Suppliers & High-grade dielectric laminates \\
\hline Arlon & $\begin{array}{l}\text { FoamClad 100, DiClad series, CuClad } \\
\text { series, IsoClad series, 25N, 25FR, AD } \\
\text { Series, AR Series, CLTE, CLTE-LC, } \\
\text { CLTE-XT, PIM Laminates, MultiClad } \\
\text { HF Series }\end{array}$ \\
\hline CLP Industries Ltd & MW laminates \\
\hline GE & GETEK, GETEK II \\
\hline Hitachi & MCL-LX-67F \\
\hline Krempel & Akaflex, PCL, KCL, GHE \\
\hline Isola Group & Astra $^{\mathrm{TM}}$, IS680, Gigaver 210/410 \\
\hline Neltec & $\begin{array}{l}\text { NL9000, N9000 Laminate system, } \\
\text { NY, NX Series, NH Series, N4000-13 } \\
\text { Series, N9000-13 RF, NH9450, N9350 } \\
\text { Series }\end{array}$ \\
\hline Polyflon & Norclad, Polyguide, CuFlon \\
\hline Rogers Corporation & 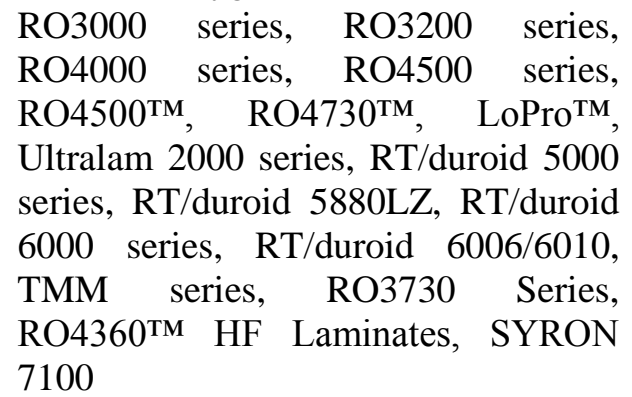 \\
\hline Sheldahl & ComClad HF \\
\hline Taconic & TLX, TLC, TLY, TLE, \& TLP series \\
\hline
\end{tabular}

Table 2 shows the list of high-grade dielectric suppliers and products [32, Tab. 2]. Common benefits of highgrade substrates are given below:

- Fitting the requirements of various microwave applications.

- Uniform thickness, a precise dielectric constant and low dissipation through the entire layer. 
- The low moisture conduction minimizes the phase shift with frequency.

- The thermally stable dielectric constant that simplifies circuit design and optimizes circuit performance. (Reduces material and fabrication costs).

- Lead-free, solder friendly, fire retardant and halogen-free (green laminates).

The majority of these well-established suppliers have active for more than 60 years. However, since the 80s, their development in the field of the dielectric substrate has increased.

\subsubsection{Basic cost of prototype}

As in all prototyping process, RF engineers calculate the basic project cost of prototyping. In this part, the basic cost will be given for fundamental patch antenna with coaxial probe feed. Basic cost includes the cost of the dielectric substrate forming the antenna, cost of labor and coaxial SMA connector. Nevertheless, the cost of the milling machine and operation nozzles or the cost of consumed energy is not included. Thus, only the cost of labor and cost of microstrip patch antenna components added to the calculation. The basic cost is given below:

- Cost of high-grade Rogers RT/Duroid 6002 substrate about A4 paper size: 100\$.

- Cost of FR4 substrate about A4 paper size: "20 - "40 (Inefficient however optional besides can be used instead of the high-quality dielectric substrate).

- Production cost: "100.

- Cost of SMA connector: "5.

The data is an updated version of the data obtained from authors 2017 work of [4], [5]. The total cost approximately varies between $\square 125$ and $\square 725$ depending on the dielectric substrate used in the patch antenna. The main factor affecting the cost of microstrip patch antenna production is the variable cost of the doublesided laminate. Furthermore, high-grade dielectric substrates can only be obtained by import. Hence, this situation is directly related to foreign currency (in this case, the US dollar); moreover, it is excessively affected by the undesired foreign exchange rate alternation.

\section{Conclusion}

The popularity of microstrip antennas is rising lately. The most important reason for this is that microstrip patch antennas can be developed for various purposes. There is a tremendous interest in microstrip patch antennas because they are lightweight compared to other antenna types, they can be produced in almost any size and shape, they are durable and can be produced in almost any condition with traditional PCB manufacturing methods. They are frequently used in countless fields such as wireless communication, medical and military fields. Specifically, they are essential for wearable technologies. For this reason, numerous researches and developments are carried out on microstrip patch antennas in universities, laboratories, research groups, and private corporations. One of the most important parts of the production and development process of microstrip patch antennas is the dielectric substrate and is also the essential element of patch antennas. Since the performance parameters of the patch antenna are built on the properties of the dielectric substrate, it is very important to be able to obtain high characteristic dielectric substrates moreover, dielectric substrates from the domestic market are insufficient for projects that require a high-grade characteristic. Highgrade substrates are generally produced, developed and distributed by the USA originated companies. Therefore, the supply of substrate depends on imports besides Turkey and developing countries are directly affected. Supplying dielectric substrates have become more challenging than before, due to unexpected fluctuations in exchange rates, monetary narrowing, and unexpected COVID-19 pandemics. High-grade dielectric substrates can only be obtained by import. Access to high-grade substrates has practically stopped when the COVID-19 pandemic is added to the unexpected fluctuation in the exchange rate and monetary problems. Besides Turkey and developing countries, this unusual situation slows down the semiconductor and 
IT industries all over the world. Due to the measures taken at the factories, the workforce has been divided, and production is carried out on duty. Furthermore, services in logistics have been limited. Such situations increased the price of the existing good while increasing the cost. As a summary, risky disruptions happen in the supply chain. Within this context, in this study, the difficulties affecting microstrip patch antenna production and design process in Turkey were examined by making the necessary literature research and benefiting from the author's microstrip antenna design and manufacturing process experience.

\section{References}

[1] I. Singh and V. S. Tripathi, "Micro strip Patch Antenna and its Applications: a Survey," International Journal of Circuit Theory and Applications, vol. 2, no. 5, pp. 1595-1599, 2011.

[2] L. C. Paul, S. Hosain, S. Sarker, M. H. Prio, M. Morshed and A. K. Sarkar, "The Effect of Changing Substrate Material and Thickness," American Journal of Networks and Communications on the Performance of Inset Feed Microstrip Patch Antenna, vol. 4, no. 3, pp. 54-58, 2015.

[3] A. Garg and A. Goen, "Substrate Height and Dielectric Constant Dependent Performance of Rectangular Microstrip Patch Antenna," International Journal of Electrical \& Electronics Research (IJEER), vol. 2, no. 3, pp. 36-39, 2014.

[4] G. K. Oğuz and Ş. T. İmeci, "A compact size circular sector patch antenna for Ku-band applications," in International Applied Computational Electromagnetics Society Symposium, Florence, Italy, 2017.

[5] G. K. Oğuz, G. Çankaya, B. F. Genç, K. İrken and Ş. T. İmeci, "T Shaped Circular Sector Patch Antenna," in Computational Methods and Telecommunication in Electrical, Sarajevo, 2018.

[6] M. Kandil, H. Berument and N. Dincer, "The effects of exchange rate fluctuations on economic activity in Turkey," Journal of Asian Economics, pp. 466-489, 2007.

[7] K. Alotaibi, "How Exchange Rate Influence a Country's Import and Export," International Journal of Scientific \& Engineering Research, vol. 7, no. 5, pp. 131-138, May 2016.

[8] C. Hacıköylü, "The Tariffs and Other Financial Obligations on the Import: Turkey and Cell Phones Import," Journal of Aksaray University Faculty of Economics and Administrative Sciences, vol. 7, no. 1, pp. 21-36, 2015.

[9] M. Kandil and N. Dinçer, "A comparative analysis of exchange rate fluctuations and economic activity: The cases of Egypt and Turkey," International Journal of Development Issues, pp. 2-38, 2008.

[10] D. Shah, R. Rajgure and T. Tandalekar, "Challenges Faced During Designing, Simulation of Microstrip Patch Antenna in HFSS and Testing After Fabrication," International Journal for Research in Applied Science \& Engineering, vol. 4, no. 4, pp. 844-847, 2016.

[11] K. Sk, S. Js and R. N. J., "Mobile Phone Addiction: Symptoms, Impacts and Causes - A Review," in International Conference on Trends in Industrial \& Value Engineering, Business and Social Innovation, Bangalore, Karnataka, India, 2019.

[12] C. A. Balanis, Antenna Theory Analysis And Design, 2nd ed., Tempe, Arizona: John Wiley \& Sons Inc., 1996.

[13] K. R. Carver and J. W. Mink, "Microstrip Antenna Technology," IEEE Transactions on Antennas and Propagation, vol. 29, no. 1, pp. 2-24, January 1981.

[14] P. Sullivan and D. H. Schaubert, "Analysis of An Aperture Coupled Microstrip Antenna," IEEE Transactions on Antennas and Propagation, vol. 34, no. 8, pp. 977 - 984, August 1986.

[15] A. K. Bhattacharyya, L. Shafai and R. Gary, "Microstrip antenna - A Generalized Tansmission Line," Progress In Electromagnetics Research, vol. 4, pp. 45-84, 1991.

[16] "IEEE," 2019. [Online]. Available: https://ieeexplore.ieee.org/Xplore/home.jsp.

[17] J. S. Pedroza, F. M. Zuñiga and M. E. Aguilar, "Planar Antennas for Satellite," in Satellite Communications, Rijeka, Croatia, InTech, 2010, pp. 368-369. 
[18] B. D. Patel, T. Narang and S. Jain, "Microstrip Patch Antenna-A Historical Perspective of the Development," in Conference on Advances in Communication and Control Systems, Mumbai, 2013.

[19] J. Duasa, "Exchange Rate Shock on malaysian Prices of Imports and Exports: An Empirical Analysis," Journal of Economic Cooperation \& Development, vol. 30, no. 3, pp. 99-113, 2009.

[20] C. A. Arize and S. S. Shwiff, "Does Exchange-Rate Volatility Affect Import Flows in G-7 Countries? Evidence from Cointegration Models," Applied Economics, vol. 30, no. 10, pp. 1269-1276, 04 October 2010.

[21] Central Bank of Turkey, "Central Bank of Turkey," 3 January 2020. [Online]. Available: https://www.tcmb.gov.tr/wps/wcm/connect/EN/TCMB+EN/Main+Menu/Statistics/Exchange+Rates/Ind icative+Exchange+Rates.

[22] S. Kutlu, "Changes in Exchange Rates and The Balance of Trade: A Literature Survey with Reference to Turkey's Foreign Trade," Atatürk Üniversitesi İktisadi ve İdari Bilimler Dergisi, vol. 27, no. 2, pp. 121-140, 14 April 2013.

[23] Y. Alkan, "Türkiye'de Dış Ticaret Açığı ile Büyüme ve Döviz Arasındaki İlişki," İnsan ve Sosyal Bilimler Dergisi, vol. 1, no. 1, pp. 54-67, 2018.

[24] H. Uslu, "Effects of Exchange Rate and Interest Rate on Foreign Trade in Turkey: An Analysis with Structural Breaks," Journal of Research in Economics, Politics \& Finance, pp. 311-334, 2018.

[25] İ. Göçer and B. Elmas, "The Effects of Real Exchange Rate Changes on Turkey's Foreign Trade Performance within the Framework of the Extended Marshall-Lerner Condition: Time Series Analysis with Multiple Structural Breaks," Journal of BRSA Banking and Financial Markets, vol. 7, no. 1, pp. 137-157, 2013.

[26] P. K. Goldberg and M. M. Knetter, "Goods Prices and Exchange Rates: What Have We Learned?," Journal of Economic Literature, vol. 35, no. 3, pp. 1243-1272, 1997.

[27] M. Kiptui , D. Ndolo and S. Kaminchia, "Exchange Rate Pass-Through: To WhatExtent Do Exchange Rate Fluctuations Affect Import Prices and Inflation in Kenya?," Central Bank of Kenya, Nairobi, 2005.

[28] Central Bank of the Republic of Turkey, "Exchange Rate Pass-Through: Is There a Magical Coefficient?," $20 \quad 012017 . \quad$ [Online]. Available: https://tcmbblog.org/wps/wcm/connect/blog/en/main+menu/analyses/exchange+rate+pass-through.

[29] A. D. Kaygisiz, "Pass-through Effects of Exchange Rate Fluctuations on Inflation: Turkey," International Review of Economics and Management, vol. 6, no. 2, pp. 117-137, 2018.

[30] N. Santhanam, "Low cost, high performance RF substrates," in International Topical Symposium on Technologies for Wireless Applications, Vancouver, BC, Canada, 1999.

[31] "R.F. Elettronica," 12 January 2020. [Online]. Available: https://www.rf-microwave.com/en/home/.

[32] Trackwise Designs Ltd, "Trackwise Designs Ltd," 10 October 2013. [Online]. Available: https://www.trackwise.co.uk/wp-content/uploads/2018/06/TR04_S ubstrate_Directory_Oct_13_AW.pdf 